\section{Stalled US plan for Plan B}

$\mathrm{L}$ evonorgestrel (Plan B) is available without a prescription in Canada and at least 38 other countries, but not in the US. There, improving access is a highly divisive issue that has led to the resignation of the Food and Drug Administration (FDA) director of women's health and an investigation by the Government Accountability Office (GAO) following allegations of political interference by the Bush Administration.

When Barr Labs first applied for over-the-counter status in April 2003, women's health advocates claimed improved access would reduce the number of unintended pregnancies, while conservative religious groups argued that the drug could lead to an early abortion. Leading Republican members of Congress urged the FDA to reject Plan B for over the counter status.

In the eye of the storm, the FDA focused on scientific evidence recalls Susan Wood, the former director of the agency's Office of Women's Health who resigned over the delays. Studies showed that the pill was extremely safe, and its availability would not lead to an increase in unprotected sex. Two FDA panels of experts voted overwhelmingly in favour of over-the-counter status in December 2003.

But in May 2004 - an election year
- the FDA turned Barr down, citing concerns that teenage women would use the pill incorrectly (despite scientific evidence to the contrary).

Members of Congress who suspected political interference asked the federal GAO to investigate. Its Nov. I4, 2005 report stated that the process was "unusual" and that the decision may have been made months before the scientific reviews were completed. It noted that it was "unprecedented" for the FDA to go against the recommendations of its advisory committee.

In addition, 3 high level officials declined to sign the letter that refused approval. The letter was sent anyway. "This action removed decision-making authority from the directors of the reviewing offices who would normally make the decision," stated the GAO.

Barr Labs reapplied in July 2004, this time asking that Plan B be available over the counter only to women over age I6; the FDA failed to issue a decision by its deadline of January 2005 . Democrats Hillary Clinton and Patty Murray delivered a ro ooo-name petition and pressured the agency to make a decision by Sept. I, 2005. Instead, the FDA announced in late August that it would solicit "public comment" before settling the issue.

This sparked demonstrations in New York and Washington, DC, and led Wood to resign after nearly 5 years at the

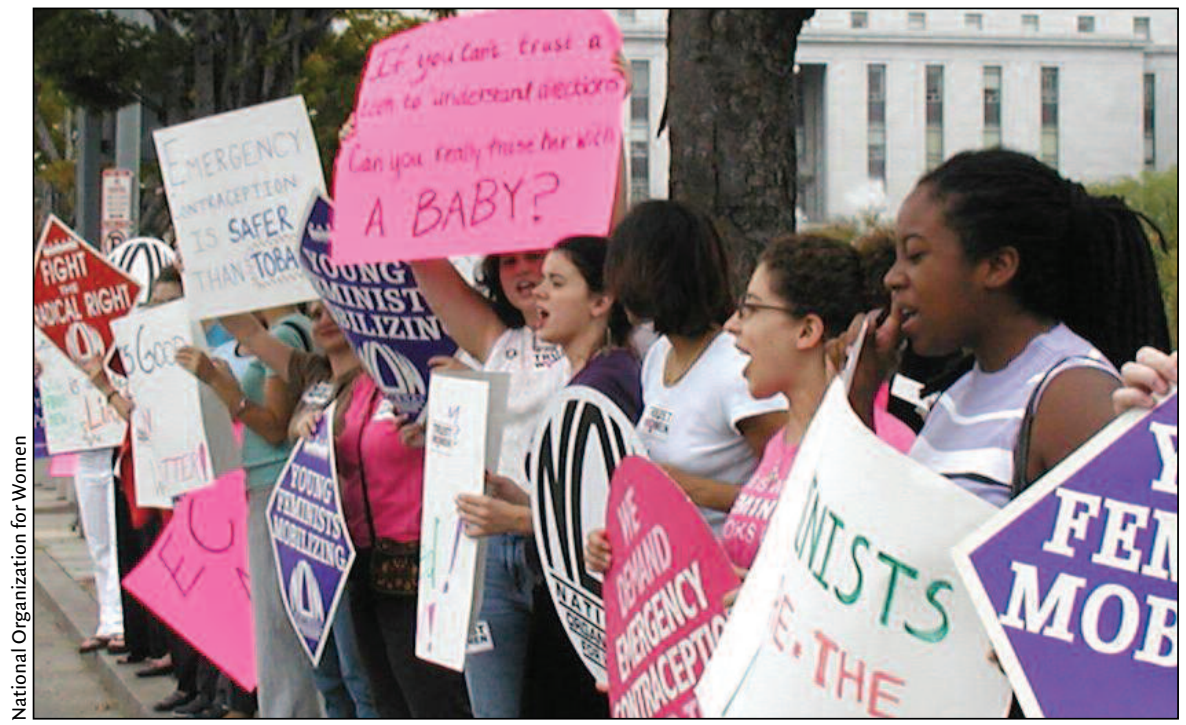

The National Organization for Women held a National Day of Action on Aug. 30 to protest the FDA's repeated refusal to approve emergency contraception for over-the-counter use. agency. The comment period ended Nov. I. FDA spokesperson Crystal Rice says the agency is reviewing more than 46000 comments and has no timeline for delivering a decision.

Two members of Congress introduced a bill on Nov. 3 that would force the agency to issue a decision on the drug's over-the-counter status within 30 days. That Bill has gone to committee for review. Its coauthor, Republican Christopher Shays says "The FDA has let ideology and politics get in the way of science.... Our legislation - if passed - will force them to act once and for all, or break the law."

In its Nov. I4 report, the GAO urges Health and Human Services Secretary Mike Leavitt, who oversees the FDA, to intervene to assure that an upcoming decision about the pill's status "is based on the best available science instead of ideology." - Miriam Shuchman, Toronto

DOI:I0.I503/cmaj.05I475

\section{Saskatchewan MDs oppose}

\section{new mandatory testing law}

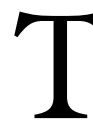

he Saskatchewan Medical Association is opposing a new provincial law that could force non-consensual blood tests for HIV/AIDS and other infectious diseases.

The Mandatory Testing and Exposure (Bodily Substances) Act, which took effect Oct. I7, allows a judge to order a test at the request of a police officer, paramedic, Good Samaritan, victim, or anyone else who believes they've been exposed to body fluids while providing emergency medical care or during a crime. The Act would only cover cases where someone refuses to get tested voluntarily.

The law, modelled on legislation drafted by the Uniform Law Conference of Canada, is the first in Canada to give a judge the authority to order a test, says Justice Minister Frank Quennell.

As part of the legislation, physicians are required to provide the court with an assessment of the level of risk the exposure created.

"This legislation is seriously flawed 